Uluslararası Mühendislik

Araştırma ve Geliştirme Dergisi UMAGD, (2019) 11(2), 496-506.

\title{
Karabük İl Merkezinde Bulunan Şehit Şendoğan Topçu İlkokulunun Bedensel Engelli Bireyler İçin Ulaşılabilirliğinin İncelenmesi
}

\section{Examination of the Accessibility for the Physically Disabled Individuals of Şehit Şendoğan Topçu Primary School in Karabük Province Centre}

\author{
Şenol Gürsoy ${ }^{1}$ (D), Cem Cüneyt Ceylan² ${ }^{\text {(D) }}$, Yüksel Turcan ${ }^{3}$ (iD \\ ${ }^{1}$ Karabük Üniversitesi, Mühendislik Fakültesi, Inşaat Mühendisliği Bölümü, 78050 Karabük, TÜRKIYYE \\ ${ }^{2}$ Karabük Üniversitesi, Safranbolu MYO, Mimari Restorasyon Programı, 78600 Karabük, TÜRKIYE \\ ${ }^{3}$ Karabük Üniversitesi, Mimarlık Fakültesi, Mimarlı Bölümü, 78600 Karabük, TÜRKIYYE
}

$\ddot{O} \mathbf{z}$

Türkiye'de engelli bireylerin mevcut fiziksel mekanlara ulaşılabilirliği için uygulanan iyileştirmelerin maalesef yasal zorunlulukları yerine getirmek amacıyla yapıldığı görülmektedir. Engelli bireylerin özellikle eğitim ve sağlık gibi toplumsal yaşama katılım süreçlerinin sorunsuz bir şekilde sağlanmasında bazı önlemlerin alınmasına ihtiyaç duyulmaktadır. Bu çalışmada Karabük ilinde bulunan Milli Eğitim bağlı okul binalarının bedensel engelli bireyler için ne derecede ulaşılabilir olduğunu incelenmektedir. Bu amaçla engelli bireylerin ulaşılabilirliği için seçilen betonarme bir okul binasının Sta4-Cad programı yardımıyla yapısal çözümlemeleri gerçekleştirilmektedir. Elde edilen sonuçlar, Milli Eğitime bağlı Karabük il merkezindeki ilk ve orta öğretim okul binalarının çoğunluğunun engelli bireylerin ulaşılabilirliği bakımından uygun olmadığını göstermektedir. Ayrıca, söz konusu okul binalarının çoğunun bugün yürürlükte bulunan Türkiye Deprem Yönetmeliğindeki koşullarını sağlamadığı ve güçlendirilmesi gerektiği görülmektedir.

\section{Anahtar Kelimeler}

"Ĕ̈itim binaları, engelli ulaşılabilirliği, engelli yönetmeliği, STA4-Cad”

\begin{abstract}
Unfortunately, it is seen that it was made in order to fulfill the legal requirements of improvements applied to the accessibility of the existing physical spaces of people with disabilities in Turkey. It is necessary to take of precautions to ensuring that the disabled people's participation of processes in social life such as especially education and health can be ensured without problems. In this study, it is examined what extent that is reached for physically handicapped individuals of the National Education affiliated school buildings in Karabük province. For this purpose, structural analysis of a reinforced concrete school building selected for the accessibility of disabled individuals is carried out with the aid of the Sta4-Cad program. The obtained results show that most of the primary and secondary school buildings in the Karabük provincial centre affiliated National Education are not suitable for the accessibility of the disabled individuals. In addition, most of the said school buildings not provide the conditions of the Turkey Earthquake regulations in force today, and it is seen that need to be strengthened.
\end{abstract}

Key Words

"Education buildings, disabled accessibility, disability regulation, STA4-Cad" 


\section{Giriş}

Türkiye'de engelli bireyler toplumsal yaşam içinde birtakım sorunlarla karşılaşmaktadırlar. Bu problemlerinin çözülmesiyle birlikte engelli bireylerin de erişilebilir bir çevreye ve daha yüksek hayat standartlarına kavuşmuş olacağı açıktır. Günümüzde tüm dünyada engellilere yönelik tasarımın gerekliliği, hatta farklı engel gruplarının yaşam çevresini kullanımlarında kolaylık sağlayan tasarımların uygulanması, bir zorunluluk haline getirilmiştir. Türkiye'de ise; engellilere yönelik tasarım çalışmalarının maalesef oldukça geç tarihlerde olduğu görülmektedir.

572 sayılı Kanun Hükmündeki Kararname (KHK) ile engellilerin ulaşılabilirliğinin ve erişilebilirliğinin sağlanmasıyla ilgili yasal düzenleme yapılmıştır (572 Sayılı KHK, 1997). 572 sayılı KHK ile yapılan bu değişikliğin ardından, Bayındırlık ve İskân Bakanlığı tarafindan ulaşılabilirlikle ilgili düzenlenen ve eklenen 3194 sayılı İmar Kanunu’nun ilgili yönetmelikleri yeniden düzenlenerek 23804 Sayılı Resmi Gazetede yayımlanarak yürürlüğe girmiştir.

Türkiye de 1982 yılında yürürlüğe giren Türkiye Cumhuriyeti Anayasasında engelli bireylerin hakları güvence altına alınmıştır. T.C. Anayasası'nın 42. maddesinde "Kimse, ĕgitim ve ögrenim hakkından yoksun bırakılamaz" hükmü ile bireylerin eğitim hakkı çok açık bir şekilde belirtilmiştir. Ayrıca 1982 Anayasasının 61. maddesinde ise "Devlet, sakatların korunmalarını ve toplum hayatına uyumlarını sağlayıcı tedbirleri alır” hükmünün yer aldığı görülmektedir (2709 Sayılı Kanun, 1982).

5378 sayılı Özürlüler ve bazı kanun ve kanun hükmünde kararnamelerde değişiklik yapılması hakkındaki kanunda eğitim hakkı düzenlemiş ve engelli olmayanlarla eşit eğitim imkanı sağlanması gerektiği belirtilmiştir. Böylelikle engelli bireylerin kendi yaşıtlarıyla birlikte eğitim alması hedeflenmiştir. Ayrıca engelli üniversite öğrencilerinin öğrenim hayatlarını kolaylaştırmak amacıyla engelliler danışma ve koordinasyon merkezi kurulması gerektiği belirtilmiştir (5378 Sayılı kanun, 2005).

222 sayılı ilköğretim ve eğitim kanununun 12. maddesinde de "Mecburi ilköğrenim çağında bulundukları halde zihnen, bedenen, ruhen ve sosyal bakımdan engelli olan çocukların özel eğitim ve ögretim görmeleri să̆lanır” şartı bulunmaktadır (222 Sayılı kanun, 1961).

Türkiye'de 2005 yılında yürürlüğe giren Özürlüler yasasıyla birlikte erişilebilirlik için 7 yıllık süre tanınmış ancak bu sürenin sonunda yapılan düzenlemeler yeterli görülmediği için 3 yıllık bir ek süre daha verilmiştir. Bu çalışmada Karabük İli kent merkezindeki Milli Eğitime bağlı ilk ve orta öğretim okul binalarının çalışma alanı olarak seçilmesindeki başlıca etken, Türkiye'de engellilerle ilgili düzenlemelerin yasal bir zorunluluk hale gelmesinden sonra, daha önceki yıllarda yapımı tamamlanmış olan okul binalarının birçok yönüyle erişilebilirlik düzeylerinin düşük olmasıdır (Gürsoy ve diğ., 2017).

Bedensel engelli çocukların, eğitim-öğretim aşamalarının daha ilk evrelerinde fiziksel çevre ve toplum tarafindan engellenmesi onun gelecekteki yaşantısını önemli derecede etkileyeceği bir gerçektir. Temel eğitimin bir hak olduğu dolayısıyla da bu haktan bütün bireylerin (eğitim çağındaki çocukların) faydalanması gerektiği düşüncesi bu çalışmasının ana temasını oluşturmaktadır. Bu nedenle, özellikle bedensel, engelli çocukların engelli olmayan çocuklarla birlikte eğitim binalarında herhangi bir engelle karşılaşmadan temel eğitimlerinin alınmasının sağlanması gerekmektedir. Bu çalışmasıyla bedensel engelli çocukların önerilecek ve/veya yapılacak tasarımlarla diğer çocuklarla birlikte eşit şartlarda eğitim görmesi sağlamak ve seçilen okul binası ile ilgili gerekli bilgileri toplayarak bazı hususlara dikkat çekmek hedeflenmektedir. Böylelikle bedensel engelli çocukların toplumsal yaşama tam ve eşit katılımı sağlanmış olacaktır.

Bu çalışmada, Karabük ili Milli Eğitim Müdürlüğüne bağlı ilk ve orta öğretim okul binalarının engelliler için ulaşılabilirliğinin incelenmesi kapsamında seçilen örnek okul binasının engelli bireylerin ulaşılabilirliği için yapılacak müdahale ve/veya iyileştirmelerin binanın davranışlarına etkisi Sta4-Cad (Sta4-Cad, 2014) programı yardımıyla karşılaştırmalı olarak incelenmektedir. Çalışmanın sonunda yapısal çözümlemelerden elde edilen bulgular karşılaştırmalı irdelenerek, engelli bireylerin ulaşılabilirliği için yapılacak müdahale ve/veya iyileştirmelerin daha güvenilir ve ekonomik tasarımlarına ilişkin bazı sonuçlar ve önerilerin sunulması hedeflenmektedir.

\section{Engelliler İçin Mekân Tasarımı}

Engelli kullanıcılar için mekânların mimari tasarımlarında, genel kullanıcılar için düşünülen temel gereksinimler ile birlikte engelli bireylerin fiziksel ve/veya psikolojik durumlarını da dikkate almak gerekmektedir. Gerçekten engelli kullanıcılar için mimari mekân tasarımı, engel durumlarından dolayı söz konusu bireylerin kısıtlanan hareketlerini hem fizyolojik hem de psikolojik donanımlar vasıtasıyla yapabilmesi ve yalnız başlarına hayatını devam ettirebilmesi sağlamalıdır. Engelli kullanıcılar için mekân tasarlanırken, söz konusu kullanıcının engelinin ne olduğu, hangi hareketleri yapmakta zorlandığı ve hangi hareketleri yapabildiği incelenmelidir. Asıl amaç engelli bireyin mekânda kimseye ihtiyaç duymadan bağımsız hareket edebilmesinin sağlanmasıdır.

Bu günkü tasarım prensipleri genellikle ortalama kadın veya erkek kullanıcılar esas alınarak oluşturulmuştur. Ancak çeşitli nedenlerle hareket kabiliyetleri kısıtlanan ve/veya hareket kabiliyetlerini büyük ölçüde kaybetmiş dolayısıyla da yardımcı ekipmanlarla hayata katılan bireyler yaşam çevresinde farklı kullanım kolaylıklarına ihtiyaç duymaktadırlar.

Yaşadığımız fiziksel çevreyi tüm bireylere yönelik planlamayı Evrensel Tasarım olarak adlandırmak mümkündür. Evrensel tasarım, tüm bireylerin taleplerine karşılık veren tasarım yaklaşımıdır. Diğer bir ifadeyle evrensel tasarım, tüm bireylerin özel 
muameleye ve ayrı tasarım çözümlerine gerek kalmadan herkesin kolayca kullanabileceği, erişilebilir olan, erişim ve kullanımda seçme özgürlüğü ve eşitlik sağlayan, güvenli ve nitelikli bir fiziksel çevreyi hedeflemektedir. Bu nedenle evrensel tasarımı, "herkes için tasarım" ve "yaşam boyu süren tasarım" biçiminde de ifade etmek mümkündür. Özetle evrensel tasarım prensibi aşağıda belirtilen ilkeleri sağladığı takdirde engelli bireylerin yaşam kalitesi en üst düzeye ulaşmış olacaktır.

1) Eşit Kullanım; Tasarım, farklı insan grupları için kullanışlı olmalıdır.

- Tüm kullanıcılar için kullanımda aynı kolaylığı sağlanmalı; mümkünse benzer, mümkün değilse eş değer uygulamalar yapilmalidir.

- Herhangi bir kullanıcıyı ayırmaktan kaçınılmalıdır.

- Mahremiyet, koruma ve güvenlik tüm kullanıcılara eşit olarak sağlanmalıdır.

- Gerçekleştirilecek tasarım tüm kullanıcılar için çekici hale getirilmelidir.

2) Kullanımda Esneklik; Tasarım farklı kişisel tercihleri barındırmalıdır.

- Kullanım yöntemleri arasında seçenekler yaratılmalıdır.

- Mümkünse sağ ve sol el erişimi ve kullanımı sağlanmalıdır.

- Tam kullanım sağlanmalıdır.

- Kullanıcı hızına uyumlu olmalıdır.

3) Basit ve Sezgisel Kullanım; Tasarım, kullanıcının tecrübesinden, dil yeteneğinden ve o anki ortama odaklanma seviyesinden bağımsız bir şekilde kolay anlaşılır olmalıdır.

- Gerekli olmayan karmaşıklık barındırılmamalıdır.

- Tasarım, kullanıcının beklenti ve sezgileri ile tutarlı olmalıdır.

- Bilgiyi önemine göre düzenlemelidir.

- İş süresince ve bitiminde aktif geri bildirim sağlanmalıdır.

4) Algılanabilir Bilgi; Tasarım, çevresel koşullara ve kullanıcının duyusal yeteneklerine bakmaksızın gerekli olan bilgiyi kullanıcıya etkin bir şekilde iletmelidir.

- Önemli bilgileri sunmak için farklı ortamlar (resimli, sözel ve kabartmalı) kullanılmalıdır.

- Önemli bilgilerin "okunabilirliğini” en üst düzeye çıkarmalıdır.

- Elemanlar tarif edilebilir şekillerde ayrıştırılmalıdır (örneğin; kullanım talimatlarını ve yön tariflerini kolay hale getirmek gibi).

- Duyusal kısıtlamaları olan bireylerin kullandıkları aygıt ve tekniklere uyum sağlayabilmelidir.

5) Hatalara Dayanım; Tasarım, kaza ya da istenmeden yapılan hareketlerin kötü sonuçlarını en aza indirmelidir.

- Elemanlar tehlike ve hataları en aza indirecek şekilde düzenlemelidir. En çok kullanılan elemanlar kolay erişilebilir, tehlikeli elemanlar ise izole edilmiş ya da korumaya alınmış olmalıdır.

- Tehlikeler ve hatalara karşı uyarılar bulunmalıdır.

- Yanlış yapmayı engelleyici düzenekler ve sistem sağlanmalıdır.

- Özellikle dikkat gerektiren işlerde bilinçsiz hareketler cesaretlendirilmemelidir.

6) Düşük Fiziksel Çaba; Tasarım, en az yorulma ile etkin ve rahat olarak kullanılmalıdır.

- Kullanıcı bireylerin doğal vücut pozisyonlarının korunması sağlanmalıdır.

- Akla uygun işletim gücü kullanılmalıdır.

- Tekrar eden hareketler en aza indirgenmelidir.

- Sürekli fiziksel çaba en aza indirgenmelidir.

7) Yaklaşım ve Kullanım İçin Yer ve Boyut; Tasarım, kullanıcısının bedensel boyutu, duruşu ve hareketinden bağımsız olarak yaklaşım, uzanım, çalıştırma ve kullanım için uygun boyutlar ve yer sağlanmalıdır.

- Oturan ya da ayaktaki kullanıcı için önemli elemanlara açık görsel bakış sağlanmalıdır.

- Oturan ya da ayaktaki kullanıcı için tüm elemanlara uzanımı kolay hale getirmelidir.

- Tasarım, el ve tutma boyutlarındaki zenginliği barındırmalıdır.

- Yardımcı araçların kullanımı ya da kişisel yardım için gerekli alan sağlanmalıdır.

\section{Sayısal Uygulama İçin Seçilen Şehit Şendoğan Topçu İlkokulu}

Bu makalede sayısal uygulaması için Şehit Şendoğan Topçu ilkokulu seçilmiştir. Çünkü söz konusu okul binasında asansör bulunmadığı ve yapının henüz ekonomik ömrünü tamamlamadığı görülmektedir. Bu amaçla öncelikle Şehit Şendoğan Topçu ilkokulunun mevcut durumu belirlemiş ve kat krokileri çizilmiştir. Daha sonra bu çalışma da incelenen söz konusu okul binasındaki bedensel engelli bireylerin ihtiyaçlarına cevap verebilecek fiziksel mekân ve elemanları başta "TS 9111 özürlü insanların ikamet Edeceği Binaların Düzenlenmesi Kuralları” standardı (TS-9111, 2011) olmak üzere çeşitli kurum ve kuruluşlar tarafindan yayımlanmış olan standartlar göz önünde alınarak değerlendirilmiştir (bkz. Çizelge 1). Sayısal uygulama için seçilen Şehit Şendoğan Topçu ilkokulu kat krokileri ve bina görünüşleri sırasıyla Şekil 1 ve 2'de verilmektedir. Ayrıca Şehit Şendoğan Topçu ilkokulunun Sta4-CAD programıla yapısal çözümlemesi için oluşturulan görünüşleri Şekil 3 'de verilmektedir. 
Çizelge 1. Şehit Şendoğan Topçu ilkokulundaki engelli bireyler için yapı öğelerinin durumu ve TSE-9111 Standardına göre mevcut yap1 öğelerinin uygunluğu

\begin{tabular}{lcccccccc}
\hline Okul Binası & $\begin{array}{c}\text { Yapım Güçlendirme } \\
\text { Yılı } \\
\text { yapılmış }\end{array}$ & $\begin{array}{c}\text { Bina girişleri } \\
\text { için rampa }\end{array}$ & $\begin{array}{c}\text { Binadaki } \\
\text { merdivenler }\end{array}$ & $\begin{array}{c}\text { Binadaki } \\
\text { asansörler }\end{array}$ & $\begin{array}{c}\text { Bina girişleri için } \\
\text { rampa } \\
\text { Standardı 90cm }\end{array}$ & $\begin{array}{c}\text { Binadaki } \\
\text { merdivenler }\end{array}$ & $\begin{array}{c}\text { Binadaki } \\
\text { Standardı 180cm } \\
\text { Standarler } \\
\text { 110x140cm }\end{array}$ \\
\hline $\begin{array}{l}\text { Şehit Şendoğan } \\
\text { Topçu ilkokulu }\end{array}$ & 1984 & $\mathrm{X}$ & $\mathrm{X}$ & $\checkmark$ & $\mathrm{X}$ & $Y o k$ & 175 & $Y o k$ \\
\hline
\end{tabular}
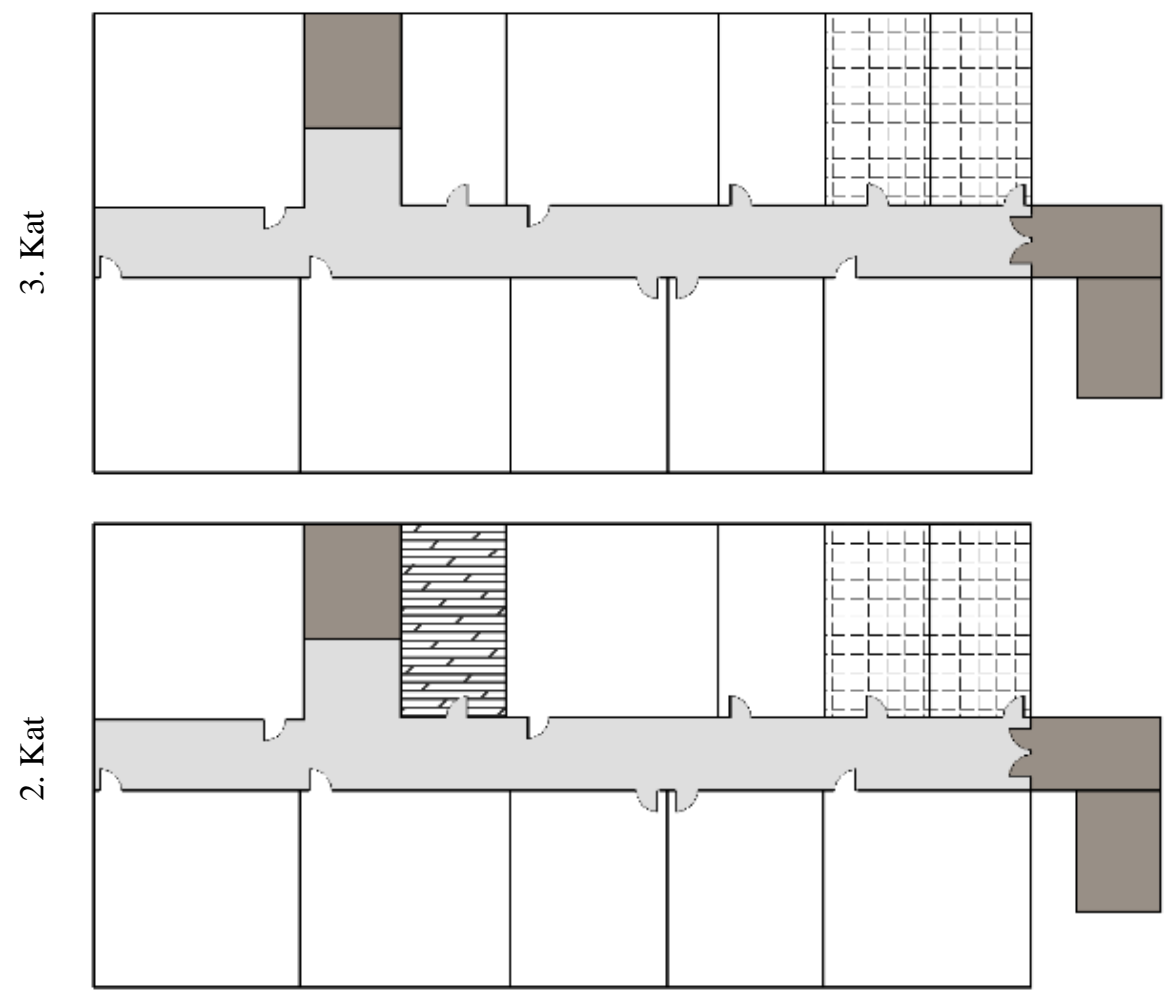

İç Merdivenler
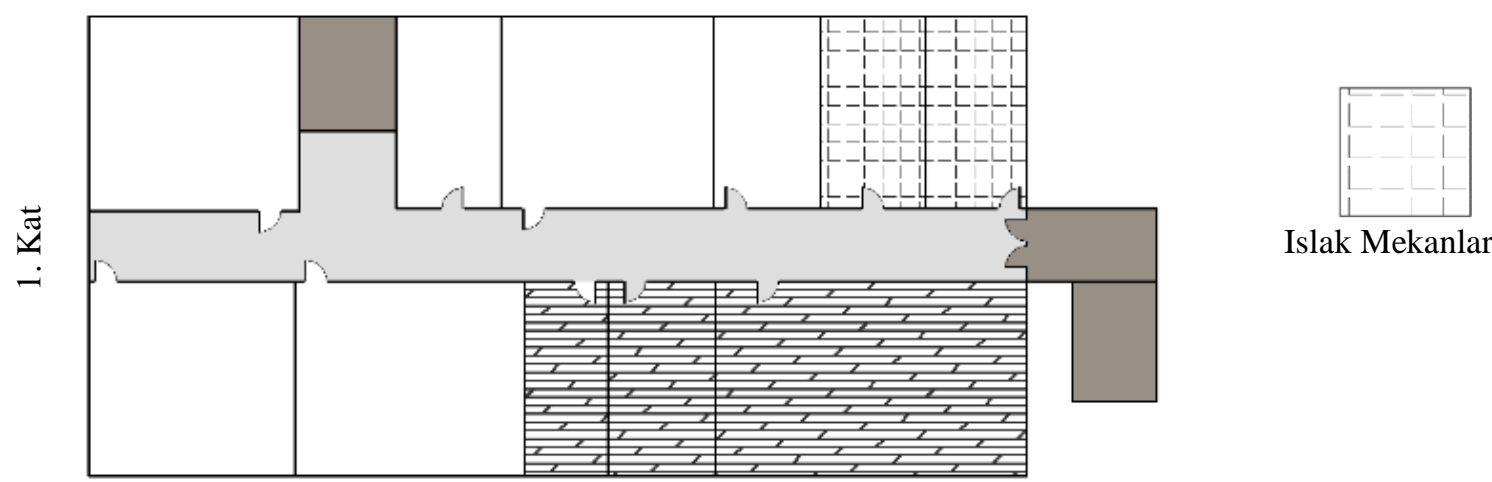

Islak Mekanlar

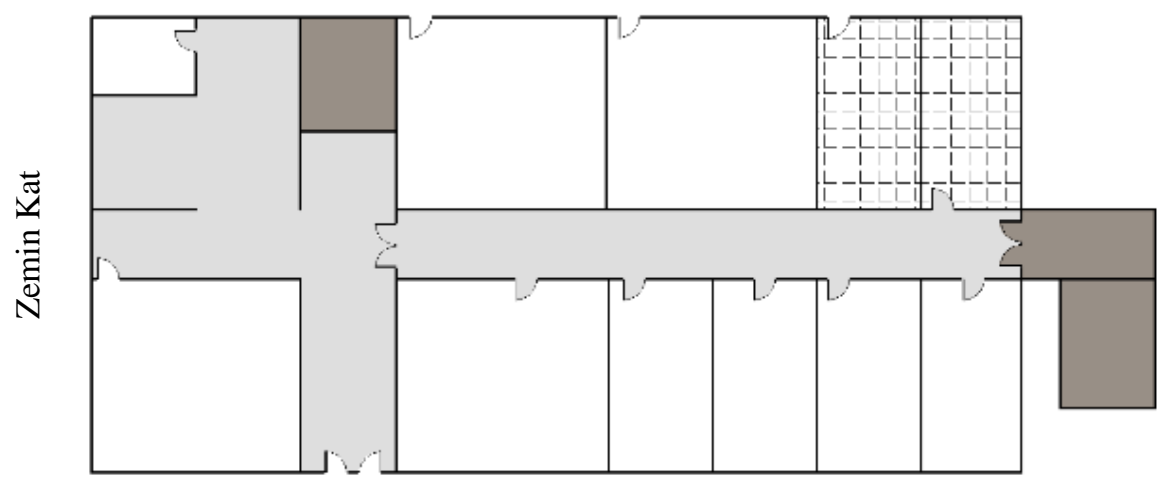

Şekil 1. Şehit Şendoğan Topçu ilkokulunun kat krokileri 

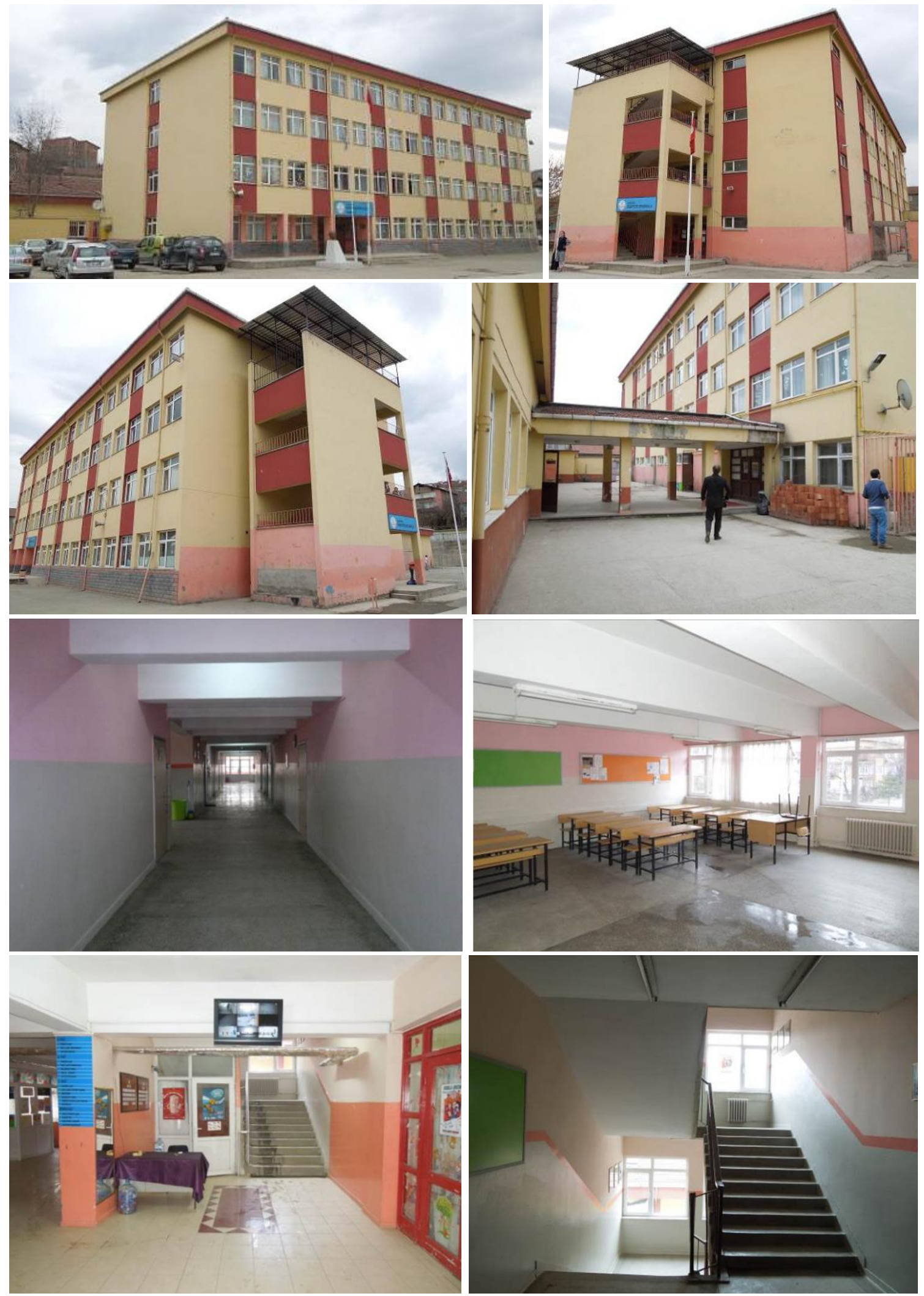

Şekil 2. Şehit Şendoğan Topçu ilkokulunun cephelerinden ve iç kısmından bazı görünümler

Bu çizelge ve şekillerden 1984 yılında yapılan Şehit Şendoğan Topçu ilkokulu zemin dahil toplam 4 kattan oluştuğu görülmektedir. Söz konusu okul binasına herhangi bir güçlendirme işlemi yapılmamıştır. Ayrıca okul binasında engelli bireylerin kullanabilec eği asansör ve rampa bulunmadığı görülmektedir (Ceylan, 2017).

Bugün yürürlükte bulunan "Betonarme Yapıların Tasarım ve Yapım Kuralları" yönetmeliğine göre (TS-500, 2000) Şehit Şendoğan Topçu ilkokulunun C16 beton ve S220 çelik sınıflarına göre tasarlandığı görülmektedir. Ayrıca yürürlükte bulunan "Deprem Bölgelerinde Yapılacak Yapılar Hakkındaki Yönetmeliğe" göre Șehit Şendoğan Topçu ilkokulu 1. derece deprem bölgesinde inşa edildiği dolayısıyla da etkin yer ivmesi katsayısının 0,4 olarak alındığı görülmektedir (TDY, 2007). Şehit Şendoğan Topçu 
ilkokulunun zemin etüd raporuna göre okul binasının Türkiye Deprem Yönetmeliğinde tanımlanan Z2 yerel zemin sınıfının C grubunda yer aldığı belirlenmiştir. Şehit Şendoğan Topçu ilkokuluna ilişkin daha önceki yapısal analizlerde dikkate alınan diğer parametreler de Çizelge 2'de özetlenmektedir.
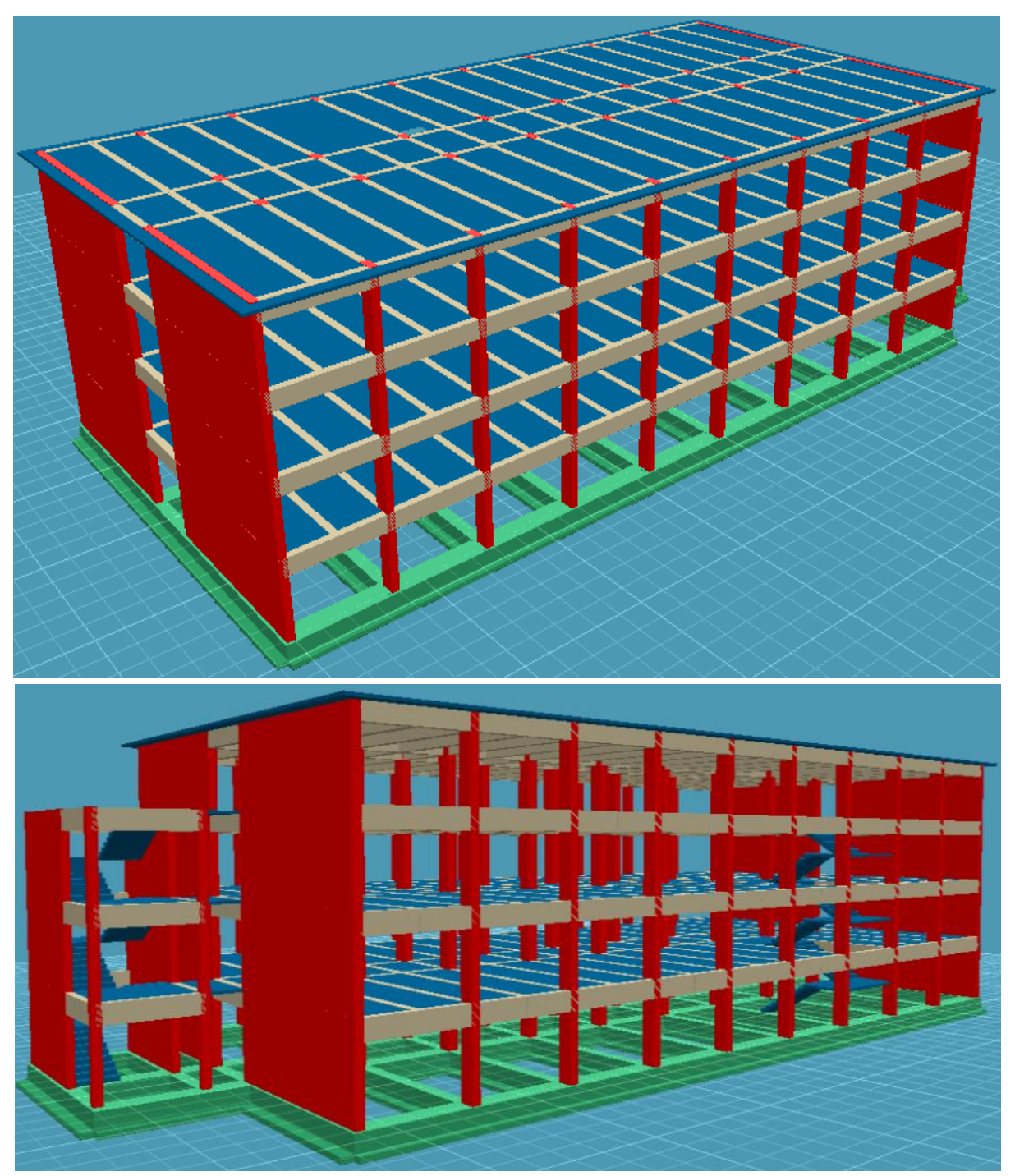

Şekil 3. Şehit Şendoğan Topçu ilkokulunun Sta4-CAD programılla oluşturulan modelinin cephelerinden bazı görünümler

Çizelge 2. Şehit Şendoğan Topçu ilkokulunun diğer proje parametreleri

\begin{tabular}{lc}
\hline Deprem bölgesi & 1 \\
Etkin yer ivmesi katsayısı $\left(\mathrm{A}_{0}\right)$ & 0,4 \\
Bina önem katsayısı (I) & 1 \\
Taşı1cı sistem davranış katsayısı (R) & 4 \\
Hareketli yük katılım katsayısı & 0,6 \\
Z2 Yerel zemin sınıfi için spektrum karakteristik peryotları $(\mathrm{s})$ & $\mathrm{T}_{\mathrm{A}}=0,15 \mathrm{~T}_{\mathrm{B}}=0,40$ \\
Z2 Yerel zemin sınıfi için temel zemini emniyet gerilmesi $\left(\mathrm{kN} / \mathrm{m}^{2}\right)$ & 125 \\
Z2-Yerel zemin sınıfı için temel zemini yatak katsayısı $\left(\mathrm{kN} / \mathrm{m}^{3}\right)$ & 20000 \\
Döşseme kalınlıkları $(\mathrm{cm})$ & 12 \\
Kirişlerin en kesit boyutları $(\mathrm{cm})$ & $30 \times 70 \mathrm{ve} 25 \times 70$ \\
Hareketli yük $\left(\mathrm{kN} / \mathrm{m}^{2}\right)$ & 3,5 \\
Kat sayıs $(\mathrm{Z}+3)$ & 4 \\
Beton sinıfi & $\mathrm{C} 16\left(\mathrm{f}_{\mathrm{ck}}=16 \mathrm{MPa}\right)$ \\
C16 Betonun elastisite modülü (MPa) & 27000 \\
Çelik sınıf & $\mathrm{S} 220\left(\mathrm{f}_{\mathrm{yk}}=220 \mathrm{MPa}\right)$ \\
S220 Çeliğinin elastisite modülü $(\mathrm{MPa})$ & 200000 \\
\hline
\end{tabular}


Bu çalışmada Milli Eğitime bağlı Karabük merkezdeki ilk ve orta öğretim okul binalarının bedensel engelli bireylerin ulaşılabilirliği için yapılacak iyileştirme (asansör ilavesi gibi) işleminin sayısal uygulamada örnek olarak seçilen Şehit Şendoğan Topçu ilkokulunun mevcut durumu matris deplasman yöntemini kullanan Sta4-CAD programıla, TDY-2007'de önerilen Z2 yerel zemin sınıfi için, depremsiz durumda gerçekleştirilen yapısal çözümlemesinden elde edilen yetersiz yapısal elemanlarının görünümü Ş ekil 4'de verilmektedir. Bu şekilden Şehit Şendoğan Topçu ilkokulunun mevcut beton ve donatı (demir) sınıfları için özellikle zemin kolonlarının çoğunun yetersiz olduğu görülmektedir. Diğer bir ifadeyle zemin kolonlarının kullanım dışı kalmasıyla binanın tamamının kullanım dışı kalacağı açıktır. Bu sonuç Şehit Şendoğan Topçu ilkokulunun mevcut durumuyla emniyetsiz olduğunu ortaya koymaktadır. Dolayısıyla Şehit Şendoğan Topçu ilkokulunun yetersiz olan yapısal elemanlarının güçlendirilmesi gerekliliği ortadadır. Durum böyle olunca yetersiz olan zemin kat kolonlarının mantolama tekniğiyle ve yetersiz temel (iki doğrultuda sürekli temel) sistemine plak (kirişsiz radye) temel sistemi ilave edilerek okul binası güvenli duruma getirilmiştir.
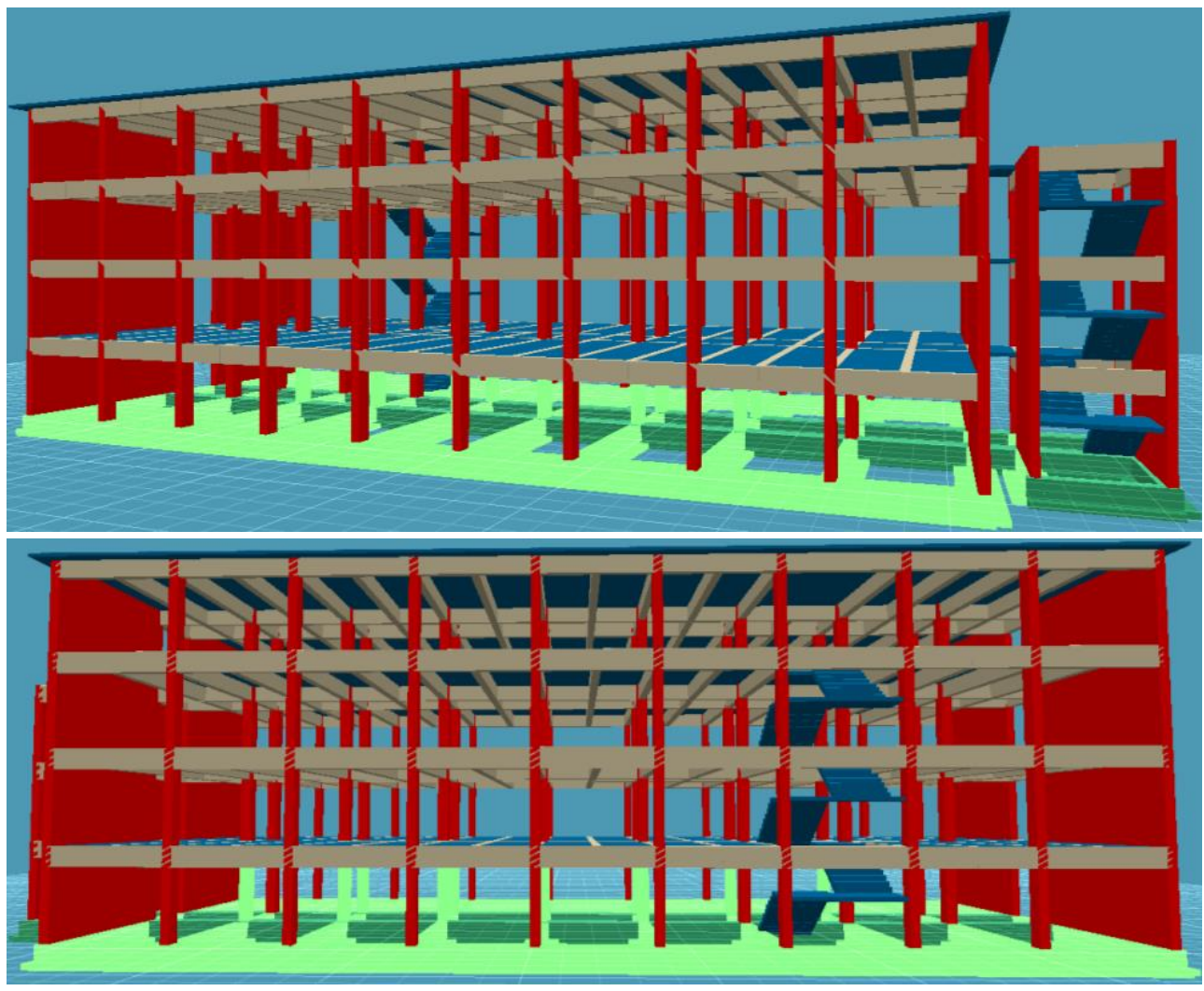

Şekil 4. Şehit Şendoğan Topçu ilkokulunun depremsiz yapısal çözümlemesinden oluşan yetersiz olan elemanlarından görünümler

Şehit Şendoğan Topçu ilkokulunun depremsiz durumdaki yetersiz olan yapısal elemanlarının güçlendirilmesiyle oluşturulmuş bina modelinin TDY-2007'deki Z2 yerel zemin sınıfı için önerilen tasarım spektrumuna göre, depremli durumda Sta4-CAD programıyla gerçekleştirilen yapısal çözümlemesinden elde edilen yetersiz yapısal elemanlarının görünümü Şekil 5'de verilmektedir. Bu şekillerden de Şehit Şendoğan Topçu ilkokulunun deprem etkisi altında güçlendirme yapılmamış özellikle zemin kat ve 1. kat kolonlarının yetersiz olduğu görülmektedir. Bu sonuçta Şehit Şendoğan Topçu ilkokulunun deprem emniyetinin olmadığını ortaya koymaktadır. Durum böyle olunca Şehit Şendoğan Topçu ilkokulunun yetersiz olan zemin kat ve 1. kat kolonları mantolama tekniğiyle güçlendirilmiştir. Diğer taraftan bu güçlendirme işlemleriyle birlikte Şehit Şendoğan Topçu ilkokuluna engelli bireylerin ulaşılabilirliği için bir asansör de ilave edilmiştir.

Burada bugün yürürlükte bulunan "Betonarme Yapıların Tasarım ve Yapım Kuralları” yönetmeliğine göre okul binasına ilave edilen asansör ve mantolama ile güçlendirmede kullanılan beton sinıfinın $C 30\left(f_{c k}=30 \mathrm{MPa}\right)$ ve çelik sinıfinın ise S420 ( $f_{y k}=420$ $\mathrm{MPa}$ ) olduğunu belirtmek uygun olacaktır.

Engelli bireylerin ulaşılabilirliği için ilave edilen asansör ve yetersiz olan yapısal elemanlarına güçlendirme işlemi uygulanmış Şehit Şendoğan Topçu ilkokulunun zemin kat planı ve bina görünüşleri Şekil 6'da ve güçlendirme işlemi uygulanmış temel sistemi ise Şekil 7'de verilmektedir. Bu şekillerden Şehit Şendoğan Topçu ilkokuluna engelli bireylerin ulaşılabilirliği için plan üzerinde farklı konumlarda asansör ilave edilebileceği, ancak okul binasının mevcut durumda emniyetinin olmadığı, gerekli emniyeti sağlamak için oldukça kapsamlı çalışmaların yapılması gerektiği görülmektedir.

Bu çalışmanın sayısal uygulamasında dikkate alınan Şehit Şendoğan Topçu ilkokulunun Sta4-CAD programı yardımıyla, TDY'de önerilen Z2 yerel zemin sınıfı için, gerçekleştirilen güçlendirilmiş depremli ve asansör ilave edilmiş modellerinin yapısal çözümlemelerinden elde edilen durumlar taban kesme kuvvetleri ve söz konusu modellere ilişkin 1. doğal titreşim periyotları (T1) Çizelge 3'de verilmektedir. Bu çizelgeden güçlendirilmiş ve asansör ilave edilmiş okul modelinin peryot değerinin güçlendirilmiş 
ancak asansör ilave edilmemiş okul modeline göre azaldığ görülmektedir. Diğer taraftan güçlendirilmiş ve asansör ilave edilmiş okul modelinin x ve y doğrultularında elde edilen taban kesme kuvvetlerinin arasındaki farkın azaldığ görülmüştür. Bu bulgular da güçlendirilmiş ve asansör ilave edilmiş okul modelinin performansının daha iyi olduğunu ortaya koymaktadır.

Çizelge 3. Şehit Şendoğan Topçu ilkokulunun depremli ve güçlendirme uygulanmış ve asansör ilave edilmiş modellerinin maksimum taban kesme kuvvetleri ve doğal titreşim peryotları değerleri

\begin{tabular}{lccc}
\hline Şehit Ş̧endoğan Topçu ilkokulunun bina modelleri & $\begin{array}{c}\text { Z2 yerel zemin sınıfına göre taban kesme kuvvetleri } \\
\text { x doğrultusu }\end{array}$ & $\begin{array}{c}\text { Periyot } \\
\text { (T1) }\end{array}$ \\
\hline Depremli model & 629,42 & 1748,58 & 1,43 \\
Güçlendirme uygulanmış model & 712,25 & 1863,17 & 1,33 \\
Güçlendirme uygulanmış ve asansör ilave edilmiş model & 822,74 & 1369,07 & 1,14 \\
\hline
\end{tabular}
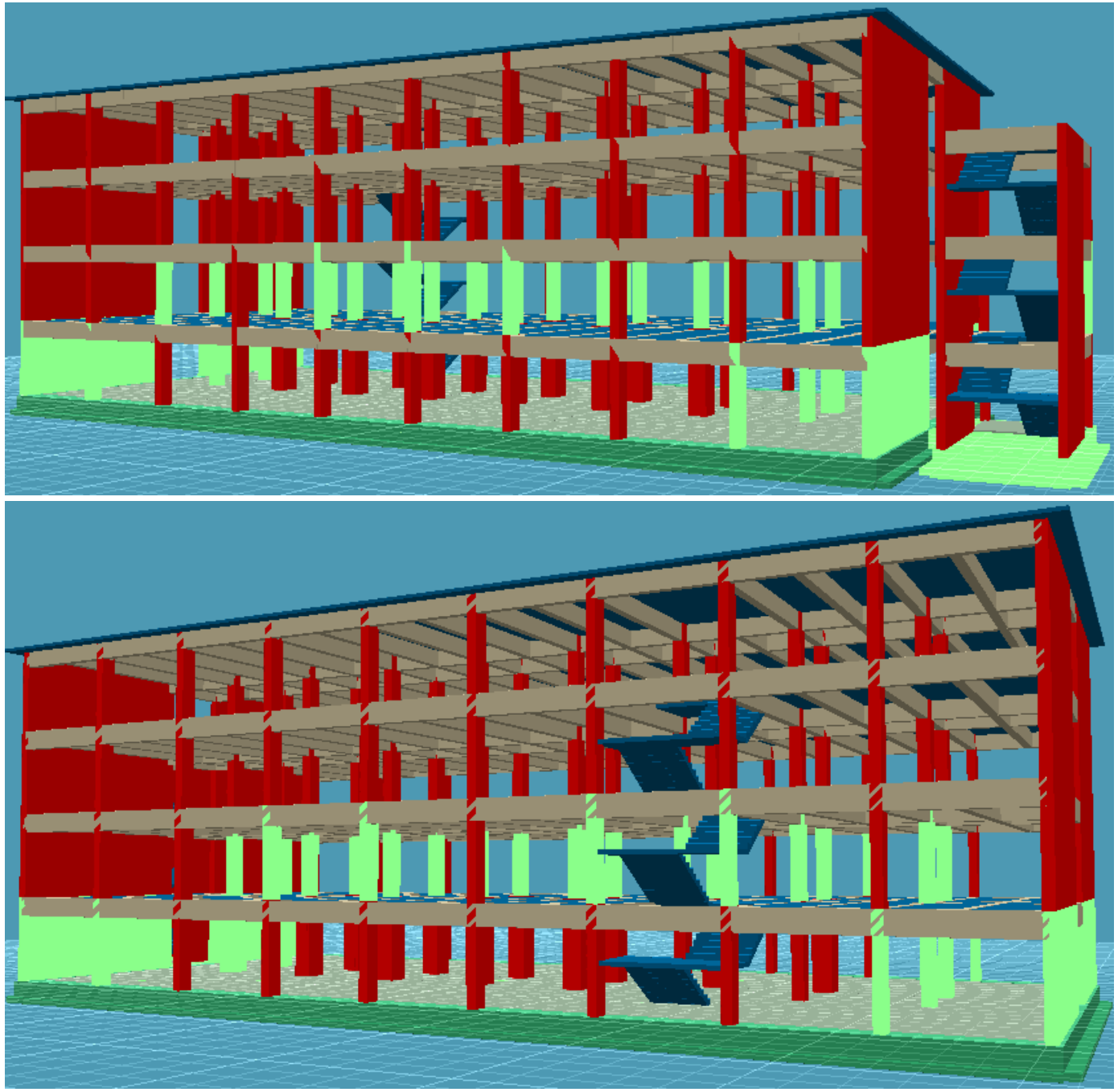

Şekil 5. Şehit Şendoğan Topçu ilkokulunun depremli yapısal çözümlemesinden oluşan yetersiz olan elemanlarından görünümler

2007 Türkiye Deprem Yönetmeliğine göre okul binalarının performans hedefleri Çizelge 4'de verilmektedir. Bu çizelgeden de görüleceği üzere okul binalarının depremler sonrası hemen kullanım (HK) ve can güvenliği (CG) koşullarının sağlaması gerekmektedir. Türkiye Deprem yönetmeliğine göre bu çizelgedeki gibi belirlenen hedef performansa (başarıma), okul gibi yapılarda 50 yılda aşılma olasılığ $\% 2$ olan deprem düzeyi kullanılmaktadır. Bu nedenle hedef deprem düzeyine göre depremin ivme spektrumu katsayısı değişmektedir. Diğer bir ifadeyle depremlerden hemen sonra kullanılması gereken binalarda; 50 yılda aşılma olasılığı \% 10 olan deprem düzeyinde hemen kullanımı sağlamalı ve 50 yılda aşılma olasılı̆̆ $\% 2$ olan deprem düzeyinde de can güvenliğini sağlamalıdır. 
Çizelge 4. TDY'ye göre farklı deprem düzeyleri için okul binalarında öngörülen performans hedefleri

\begin{tabular}{|c|c|c|c|}
\hline \multirow[b]{2}{*}{ Binanın Kullanım Türü } & \multicolumn{3}{|c|}{ Depremin Așılma OlasılığI } \\
\hline & $\begin{array}{c}50 \text { yilda } \\
\% 50\end{array}$ & $\begin{array}{c}50 \text { yılda } \\
\% 10\end{array}$ & $\begin{array}{c}50 \text { yılda } \\
\% 2\end{array}$ \\
\hline $\begin{array}{l}\text { Yoğun } \mathrm{Ol} \\
\text { rtlar, pans }\end{array}$ & - & HK & CG \\
\hline
\end{tabular}
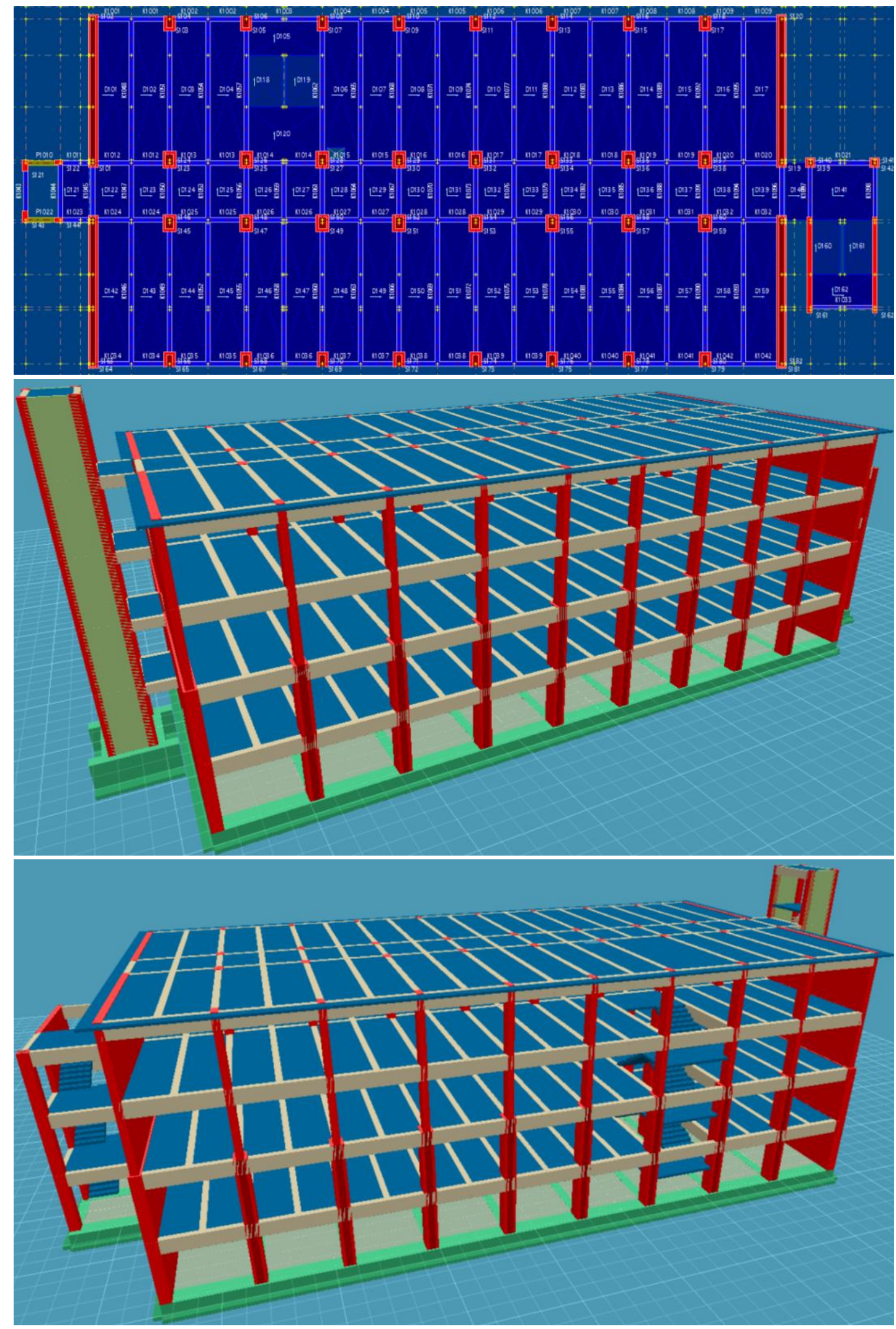

Şekil 6. Şehit Şendoğan Topçu ilkokulunun yetersiz olan yapısal elemanlarına uygulanan güçlendirilme işlemi ve engelli bireylerin ulaşılabilirliği için ilave edilen asansörle birlikte planı ve bazı görünümleri 


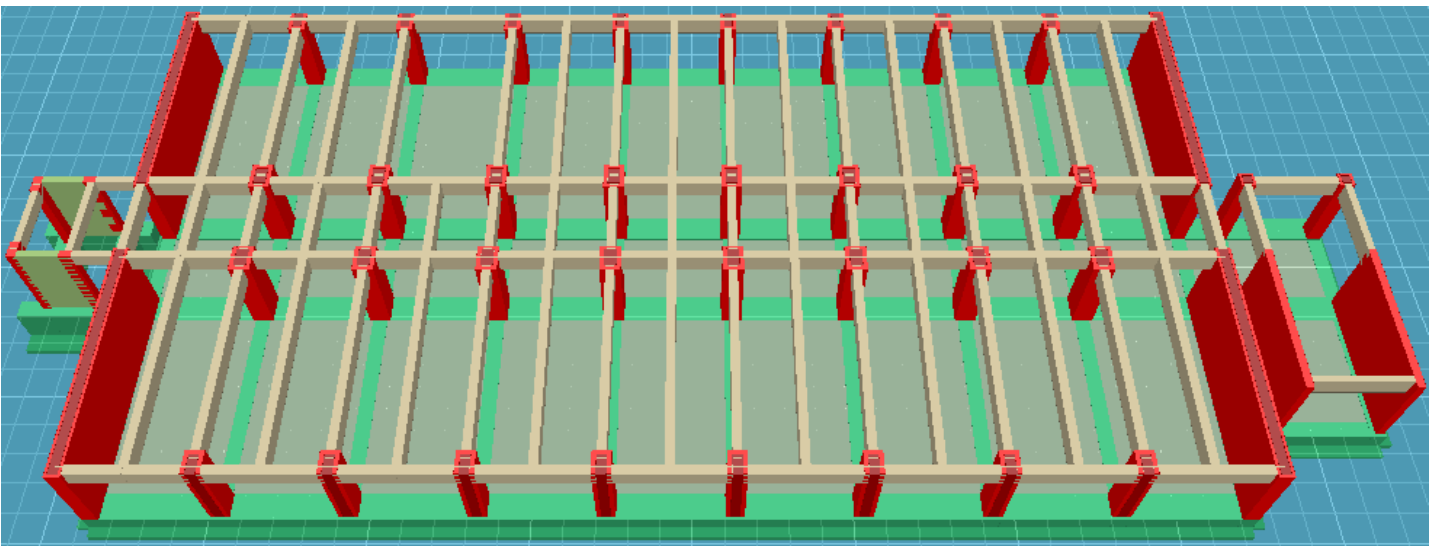

Şekil 7. Şehit Şendoğan Topçu ilkokulu nun temel sistemine uygulanan güçlendirilme işlemi ve engelli bireylerin ulaşılabilirliği için ilave edilen asansörün temelinden bir görünüm

Burada hedef performans olarak belirlenmiş olan can güvenliği performansının sağlanmaması durumunda, can güvenliği performansı sağlanıncaya kadar güçlendirmeye işlemine devam edilmesi gerektiğini belirtmek yararlı olacaktır.

Şehit Şendoğan Topçu ilkokulu nun Türkiye Deprem Yönetmeliğine göre 50 yılda aşılma olasıllğ̆ $\% 2$ olan deprem düzeyinde can güvenliği dikkate alınarak gerçekleştirilen yapısal çözümlemeden elde edilen binanın yatay yük taşıma kapasiteleri Çizelge 5'de verilmektedir. Bu çizelgeden de okul binasının $\mathrm{x}$ ve y doğrultularında yatay yük taşıma kapasitelerinin önemli derecede arttığ görülmektedir. Elde edilen bu bulgu da Şehit Şendoğan Topçu ilkokulunun mevcut durumuyla yeterli deprem emniyetine sahip olmadığını göstermektedir.

Çizelge 5. Şehit Şendoğan Topçu ilkokulunun can güvenliğine göre gerçekleştirilen yapısal ç̧̈zümlemeden elde edilen yatay yük taşıma kapasite değerleri

\begin{tabular}{ccccccc}
\hline $\begin{array}{c}\text { Kat } \\
\text { No }\end{array}$ & $\begin{array}{c}\text { Deprem Yükü } \\
\left(\mathbf{V}_{\mathbf{e}}\right)\end{array}$ & $\begin{array}{c}\text { Mevcut Okul Ooul } \\
\left(\mathbf{V}_{\mathbf{r}}\right)\end{array}$ & $\begin{array}{c}\text { Güçlendirilmiş Okul } \\
\left(\mathbf{V}_{\mathbf{r}}\right)\end{array}$ & $\begin{array}{c}\text { Deprem Yükü } \\
\left(\mathbf{V}_{\mathbf{e}}\right)\end{array}$ & $\begin{array}{c}\text { Mevcut Okul Ooul } \\
\left(\mathbf{V}_{\mathbf{r}}\right)\end{array}$ & $\begin{array}{c}\text { Güçlendirilmiş Okul } \\
\left(\mathbf{V}_{\mathbf{r}}\right)\end{array}$ \\
\hline 4 & 324,22 & 273,66 & 273,66 & 790,40 & 1356,40 & 1356,40 \\
3 & 422,49 & 400,65 & 400,65 & 1263,69 & 1250,83 & 1259,78 \\
2 & 551,62 & 604,27 & 900,16 & 1546,23 & 1077,10 & 2250,33 \\
1 & 641,02 & 674,44 & 991,03 & 1676,86 & 945,55 & 2356,59 \\
\hline
\end{tabular}

Burada bu hesaplamaların yapısal elemanların hasar düzeyini bulmada kullanıldı̆̆ını, yatay yük kapasitelerinin binanın güçlendirmesinde öngörü verdiğini ve binadaki kapasite artışının gözlenebildiğini belirtmek uygun olacaktır.

\section{Sonuçlar ve Öneriler}

Bu çalı̧̧mada engellilere yönelik tasarım prensipleri ve gerekli mekânsal ölçüleri dikkate alınarak bedensel engelli bireyler için Karabük İl Milli Eğitim Müdürlüğüne bağlı Şehit Şendoğan Topçu ilkokulunun engelliler için ulaşılabilirliği incelenmiştir. Bedensel engelli bireylerin söz konusu okul binasina ulaşılabilirliği için çözüm önerileri sunduğumuz bu çalışmadan elde edilebilen başlıca sonuç ve öneriler aşağıda özetlenmektedir.

- Gerçekleştirilen araştırma sonucunda yeni ve eski yapılmış olan Karabük ili ilk ve orta öğretim binalarında tespit edilen sorunların hemen hemen aynı olduğu görülmektedir. Özellikle yeni yapılmış binalarda da aynı sorunların olması tasarımcılar, uygulayıcılar ve denetimciler tarafindan maalesef dikkate alınmayan sürecin göstergesi olarak karşımıza çıkmaktadır.

- Şehit Şendoğan Topçu ilkokulunun güçlendirilmiş ve asansör ilave edilmiş modellerinin yapısal çözümlemelerinden $x$ doğrultusunda \%47 49 ve y doğrultusunda \%110 149 yatay yük taşıma kapasitelerinin arttı̆̆ı görülmektedir.

- Ülkemizde son yıllarda önem verilmeye başlanan engelli bireylere uygun tasarım ilkeleri her konuda daha çok geliştirilmeli ve bunların uygulamasına dikkat edilmelidir. Diğer bir ifadeyle bir gün herkesin engelli olabileceği gerçeğini unutmadan engeliler için gerekli yasal ve mimari düzenlemeler yapılmalıdır.

- Engellilerin erişebilirliliği açısından yapılacak ek müdahalelerin okul binalarında diğer tasarım ölçütlerini (mekânsal alan gerekliliği gibi) olumsuz etkileyebileceği göz önünde bulundurulmalıdır.

- Gerçekleştirilmiş olan bu çalışmayla yapım yıllarına bakıldığında Karabük İl Milli Eğitim Müdürlüğüne bağglı ilk ve orta öğretim okul binalarının yeterli emniyette olmadığı dolayısıyla da mutlaka takviye edilmesi (güçlendirilmesi) gerektiği ve engelliler için ulaşılabilirliği ile ilgili önemli sorunların olduğu görülmektedir. 


\section{Teşekkürler}

Bu çalışma Karabük Üniversitesi Bilimsel Araştırma Projeleri Birimince desteklenmiştir. Proje Kod No: KBU-BAP-14/1-YL-021.

\section{Referanslar}

222 Sayılı kanun, (1961). İlköğretim ve eğitim kanunu, 10705 Sayılı Resmî Gazete.

572 Sayılı KHK, (1997). 572 Sayılı bazı kanunlarda değişiklik yapılmasına ilişkin kanun hükmünde kararname, 23011 Sayılı Resmî Gazete.

2709 Sayılı kanun, (1982). Türkiye Cumhuriyeti Anayasası, 17863 Mükerrer Sayılı Resmî Gazete.

5378 Sayılı kanun, (2005). Engelliler hakkında kanun, 25868 Sayılı Resmî Gazete.

Ceylan, C.C, (2017). Engelsiz erişim açısından Karabük ilinde bulunan ilk ve orta öğretim okul binalarının incelenmesi, Yüksek Lisans Tezi, Karabük Üniversite, Karabük, Türkiye.

Gürsoy, Ş. Ceylan, C.C. ve Turcan, Y. (2017). Accessibility Condition of Primary and Secondary School Buildings for Disabled People in the City of Karabük, J. Int. Environmental Application \& Science, 12(3), 238-243.

Sta4-CAD, (2014). Structural analysis for computer aided design, ver.13.1. www.sta.com.tr

TDY-2007, (2007). Deprem bölgelerinde yapılacak binalar hakkında yönetmelik, Bayındırlık ve İskan Bakanlığı, Ankara/Türkiye. TS-500, (2000). Betonarme yapıların tasarım ve yapım kuralları, Türk Standartları Enstitüsü, Ankara/Türkiye.

TS-500, (2000). Betonarme yapıların tasarım ve yapım kuralları, Türk Standartları Enstitüsü, Ankara/Türkiye.

TS-9111, (2011). Özürlüler ve hareket kısıtlılığı bulunan kişiler için binalarda ulaşılabilirlik gerekleri, Türk Standartları Enstitüsü, Ankara/Türkiye. 